
\title{
$\begin{array}{ll}\text { Research Square } & \begin{array}{l}\text { Preprints are preliminary reports that have not undergone peer review. } \\ \text { They should not be considered conclusive, used to inform clinical practice, } \\ \text { or referenced by the media as validated information. }\end{array}\end{array}$
}

\section{Assistive Technology to Promote Participation in Sport for People with Disabilities}

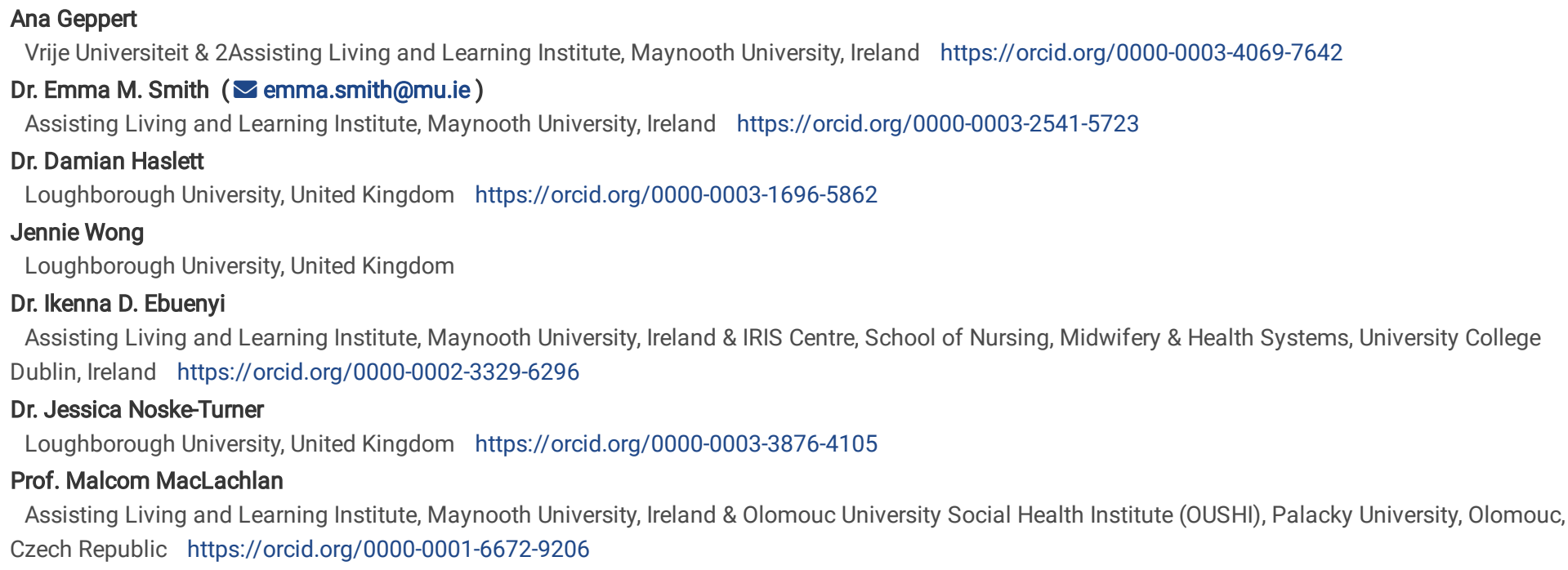

\section{Research Article}

Keywords: Assistive products, Assistive technology, Sport, disability, Parasport, Social inclusion

Posted Date: January 13th, 2022

DOI: https://doi.org/10.21203/rs.3.rs-1250239/v1

License: (우 (i) This work is licensed under a Creative Commons Attribution 4.0 International License. Read Full License 


\section{Abstract}

Participation in sports is a fundamental right for persons with disabilities and is facilitated by the use of specialized Assistive Technology (AT). However, little is known about the role every-day AT plays in promoting sport participation. This study explores how the 50 priority assistive products on the World Health Organization's Assistive Products List can promote participation in sports, using a mixed-methods online survey with AT users, caregivers, and coaches $(n=96)$. We used a thematic analysis for qualitative responses describing the use of assistive products in facilitating sport participation. Results suggest every-day assistive products are required for participation in sport for persons with disabilities. We present a conceptual model of assistive product use for sport participation. We found persons with disability participate in a range of sports, contributing to community engagement. Access to every-day assistive products is therefore integral to achieving rights of persons with disabilities for participation in sport.

\section{Full Text}

There are now a range of international sports policies and instruments that recognise the importance of including the most marginalized in sport. The United Nations General Assembly of 2018 adopted resolution (A/RES/73/25) describing "Sport as an enabler of sustainable development", with particular reference to achieving the Sustainable Development Goals (UN, 2015). The Human Rights Council Resolution (A/RES/HRC/37/18) Promoting Human Rights through Sport and the Olympic Ideal, is an explicit and emphatic statement of the link between engaging in sport and realising rights. A plethora of other policy instruments also emphasize the importance of social inclusion in sport; including the Kazan Action Plan (UNESCO, 2017), the Global Action Plan on Physical Activity (WHO, 2019), the UN Action Plan for Sport for Development and Peace (Assembly, 2018) and the International Charter of Physical Education, Physical Activity and Sport (UNESCO, 2015).

According to the Kazan Action Plan, Sport can be broadly understood as "everything from physical play, recreation, dance, organized, casual, competitive, traditional and indigenous sports and games in their diverse forms" (UNESCO, 2017). Participating in sports is important for people with disability and is recognized as a fundamental right for persons with disabilities, set out by the United Nations Convention on the Rights of Persons with Disabilities (CRPD). In particular, the CRPD identifies the right of people with disability to engage with culture through sports (UN, 2006). In addition, enhancing participation in sports helps to promote community participation and social inclusion (Bailey*, 2005; UN, 2006). Efforts to promote full participation in sport are promoting social justice (Allan et al., 2018). Article 30 of the CRPD, which entered into force in May 2008, supports the engagement of a person with disabilities in mainstream recreational sporting activities in addition to disability-specific sporting and recreational activities to the fullest extent possible. Social justice includes social inclusion, which according to Simplican et al., stands on the two pillars of interpersonal relationships and community participation (Simplican et al., 2015). These two pillars are central to a person's quality of life (Schalock et al., 2005).

Sport participation provides a range of benefits to all people including persons with disabilities (Eigenschenk et al., 2019; Warburton et al., 2006). The positive effects emerging from participation in sports have been well documented on both an individual level (e.g. improved mental health and physical health and wellbeing), as well as at a societal level (e.g. community engagement, active citizenship) (Bragaru et al., 2011; Eigenschenk et al., 2019; Saxena et al., 2005; Warburton et al., 2006). (Martin, 2013) suggested that the benefit of participation in sport might be even greater for people with disabilities. On an individual, physical level, engaging in sports by actively exercising (e.g., walking, running, swimming) is associated with reduction in obesity and a reduction in cardiovascular diseases (Adams \& Linke, 2019). Some of the health challenges which people with disabilities experience, such as rates of obesity compared to people without disabilities, may be partially addressed through participation in sport (Martin, 2013).

Despite the benefits of participation in sports, studies show that overall participation in sports seems to be lower in people with disabilities compared to people without (England, 2017; Ginis et al., 2010; van den Berg-Emons et al., 2010). This low participation rate in sports can be attributed to systemic and social barriers, which people with disabilities often face. Considering the social-relational model of disability that explains disabling barriers in context (Thomas, 1999), barriers may exist at intrapersonal (e.g., negative self-perceptions, impairment effects), interpersonal (e.g., lack of social support, negative societal attitudes), institutional (e.g. building design), community (e.g., excluding educational contexts) and policy (e.g., inaccessible public transportation) levels (Martin Ginis et al., 2016). An analysis of State's Parties reports on sport as part of the legal obligations of countries who are signatories to the Convention on the Elimination of All Forms of Discrimination Against Women (CEDAW) and the CRPD, found relatively little mention of sport in each of them (Yelamos et al., 2020).

Lack of access to critical assistive technologies, which promote or enable participation in sports, also constitutes a major barrier (WHO, 2018). The World Health Organization (WHO) distinguishes between assistive technology and assistive products. Assistive technology (AT) being the application of organized knowledge and skills related to assistive products and being a subset of health technology (WHO, 2016). Assistive Products (AP) are defined by the WHO's Global Corporation on Assistive Technology (GATE) as "any external products (devices, equipment, instrument or software), with the primary purpose to maintain or improve an individual's functioning and independence, and thereby promote well-being"(WHO, 2016). These products have the potential to play an important role in sport participation. However, there is insufficient access, with only 1 in 10 globally having access to the AT they require (WHO, 2018). Moreover, despite an obvious importance of inclusion in sports, Evans et al. (2018) noted that research and attention seem to be lacking regarding the quality of participation in sports that people with disability experience (Evans et al., 2018). Hill et al. emphasized how AT allows athletes with disabilities to perform at extraordinary levels (Hill et al., 2014). This statement would put into question some of the existing definitions of disability and support the medical model (Wasserman et al., 2016) in reaffirming that athletes with disabilities are merely conditioned by a physical impairment, which AT can simply "fix". Moreover, the statement by Hill is a common focus, in which AT and AP only are associated or related to sports at an elite level (High performing / Professional level) (Burkett, 2010; Hill et al., 2014; Marques \& Alves, 2021; Wasserman et al., 2016). In line with this, the 
Magalhaes et al. study, showed the positive effects Paralympics have had on the perceptions of every-day AT users (Magalhaes et al., 2019). However, this type of technology is not only relevant at an elite-athlete level. AT can enhance quality of life among people who use AP in their every-day life.

While there has been research on the use of AT to enable elite level parasport (Burkett, 2010), there is substantially less discussion about the potential for every-day AP to promote sports participation. This is an important omission since AP enable people to engage in sports across a huge spectrum of participation, from watching to practicing (Bryant \& Bryant, 2011). The definition of Participation in Sport is included with in the WHO's International Classification, Disability and Health (ICF) framework as "involvement in a life situation" (WHO, 2001). In this study we are using three interrelated concepts: participation, engagement, and performance. Participation in sport is being used as an umbrella term which encompasses both engagement with sport and sport's performance. By engagement in sport, in this research we refer to watching and fandom/supporting, whilst when using the term performance in sport we refer to playing and training. In the absence of a framework for levels of participation in sport for people with disabilities, our research assumes two interconnected aspects of sport participation, engagement and performance, as seen in Figure 1.

[Insert Figure 1 here]

There is therefore a gap in our understanding with respect to every-day assistive products and how these can enable participation in sports. The World Health Organization's Global Cooperation on Assistive Technology (GATE) Initiative has published a priority list of 50 assistive products, which the member state governments should provide to their citizens who need them (WHO, 2016). The Priority Assistive Products List (APL) includes 50 items which are designed and aimed for older people and people with disabilities to live a "healthy productive and dignified life" (WHO, 2016). The APL refers to highly needed products which represent a necessity in maintaining or improving an individual's functioning and need to be available and affordable for the community or state in question (WHO, 2016). Understanding how these products promote realisation of rights for persons with disabilities will provide governments and decision makers with additional understanding of how the provision of AT may help to achieve their commitments to the CRPD. Furthermore, understanding AP use in sport will lead to compelling stories, to help governments, civil society organisations and people living with disabilities take important next steps to enhance access to AT. Therefore, the purpose of this study is to understand how every-day assistive products impact participation in Sport.

Objectives

The specific objective of this research was to understand how the GATE Priority Assistive Product support sport participation for people with disabilities at all types of participation. The secondary objective was to develop a theoretical model of assistive technology and sport participation.

\section{Materials And Methods}

\section{Study Design}

This research project employed a mixed methods online survey. Online surveys can be effective tools to reach and include a broad range of participants and thereby greater diversity of experiences (Braun et al., 2020; Braun et al., 2017).

\section{Participants}

We included AP users, 18 years or over as well as caregivers, coaches or teachers who support, teach or coach AP users. While we were primarily interested in the experiences of AP-users, we recognized the value of the perspectives of coaches and teachers who are regularly involved in adaptive sport and therefore provide a valuable secondary source. Participants were recruited through contact with a variety of national and international AT organizations, the International Disability Alliance, and personal networks of the investigators, who have considerable experience working with adaptive sport organizations. These umbrella organizations and contacts were then asked to forward the request to smaller partner organizations thereby reaching a large range of organizations at a global level. We also employed social media (i.e., Twitter, Linkedln) for survey distribution.

\section{Data collection}

The online survey was created and distributed using Qualtrics software. The survey design allowed each participant group (AP users, care-takers and coaches/teachers) to exclusively answer questions relevant to them. For example, while AP users were able to report on their own experience of sport participation, coaches, teacher and caregivers were asked to report on their perception of AP use and sport participation, across all individuals they may have worked with. Each branch (category of stakeholder) had three blocks of questions: 1) Demographic information; 2) Use of Assistive Products; 3 ) Experience with Assistive Products. Demographic questions included: age, country of residence, gender, education level, employment status, living situation, primary condition requiring AT, time being AT user. The questions in both Use of Assistive Products and Experience with Assistive products were designed to assess the experiences to each of the 50 products on the APL. The survey used both closed-and open-ended questions. Questions on age and education and were closed-ended (multiple choice). Questions including gender, primary condition/impairment, and use of AP, were open-ended. To collect data regarding sport participation and AP use for each of the 50 products on the APL the participants were asked to identify the products they used regularly subsequently they were asked: "You indicated you use [Selected Assistive Product]. Please describe how [Selected Assistive Product] facilitates your engagement in sport".

Open-ended questions provide the opportunity for participants to provide their experience in an unstructured, as well as reducing bias with fixed response options (Neuert et al., 2021). The survey was piloted amongst a group of AP users for content, language and accessibility and adapted prior to distribution. 
Survey records $(n=96)$ were included for analysis if the respondent had answered at least one non-demographic question related to sports and/or AP use. While we collected both quantitative and qualitative data this paper reports on results of the qualitative data only. Data analysis of both closed-ended as well as open-ended questions of the survey, was performed using Microsoft Excel. Demographic data was analyzed using count and proportions. For the open-ended questions we used a inductive thematic analysis including open, axial and selective coding (Bragg \& Pritchard-Wiart, 2019). Codes which were similar were grouped together into themes and discussed during a research-team session to develop a sport pathway framework for further analysis. Using this framework, another round of coding was performed to refine the themes. The continued analysis provided an opportunity for iterative development of the framework.

\section{Results}

Results are presented by data type. Quantitative results are presented first, followed by results from thematic analysis. Thematic analysis results are presented in the context of a conceptual model proposed from the qualitative results.

\section{Demographics}

The respondents' $(n=96)$ reported 36 different countries of residence, from all WHO Health Regions (see Table 1). The highest percentage of the respondents (66.23\%) were coaches/teachers, followed by AP users $(23.77 \%)$ and caregivers $9.84 \%$. The mean age of AT users was 45 years (SD=14.01). Over half (59.10\%) of the AP users identified as a man. Regarding the level of education of the AP users, the majority hold a master's degree (see table 2 ). The majority of AP users reported using their respective APs for over 15 years. Participants reported participation in a great range of different sportdisciplines, as well as a wide range of impairments, as visible in Table 1.

Table 1. Survey Respondent Demographics:

\section{Countries of residence grouped by WHO Health Regions}




\begin{tabular}{|c|c|}
\hline WHO Regions & Country count (n) \\
\hline African (AFR) & 11 \\
\hline Americas (AMR) & 5 \\
\hline Europe (EUR) & 12 \\
\hline Eastern Mediterranean (EMR) & 1 \\
\hline South East Asian (SEAR) & 3 \\
\hline Western Pacific (WPR) & 3 \\
\hline \multicolumn{2}{|l|}{ Respondent's level of education } \\
\hline Level of Education (AT users) & Percentage (\%) \\
\hline Secondary school & $8.70 \%$ \\
\hline College diploma & $8.70 \%$ \\
\hline Bachelor's degree & $21.74 \%$ \\
\hline Master's degree & $47.83 \%$ \\
\hline Doctoral degree & $13.04 \%$ \\
\hline \multicolumn{2}{|l|}{ Age and Age-groups } \\
\hline Respondents & Respondents \\
\hline \multirow[t]{2}{*}{ AT-user } & Mean: 44.78 \\
\hline & Standard deviation: 14.01 \\
\hline \multirow[t]{6}{*}{ Caregiver's AT-user/s } & $0-5(9.09 \%)$ \\
\hline & $6-12(18.18 \%)$ \\
\hline & $13-18(18.18 \%)$ \\
\hline & $19-50(22.73 \%)$ \\
\hline & $51-75(18.18 \%)$ \\
\hline & $75+(13.64 \%)$ \\
\hline \multirow[t]{6}{*}{ Coach's AT-user/s } & $0-5(5.71 \%)$ \\
\hline & $6-12(19.05 \%)$ \\
\hline & $13-18(20.00 \%)$ \\
\hline & $19-50(36.19 \%)$ \\
\hline & $51-75(14.29 \%)$ \\
\hline & $75+(4.76 \%)$ \\
\hline \multicolumn{2}{|c|}{ Self-reported Impairment categories } \\
\hline Impairment categories & Self-reported impairment count (n) \\
\hline Neurological & 11 \\
\hline Musculoskeletal & 22 \\
\hline Developmental & 17 \\
\hline Sensory & 4 \\
\hline
\end{tabular}

The survey-respondents listed a great range of sports AT users participate in. These included (but were not limited to) boccia, wheel-chair yoga and cycling, powerchairfootball, cyclocross and rock-climbing.

Moreover, in relation to the question why sport is meaningful to the respondent, we got answers such as: "Engagement in sports is empowering", "it builds self-confidence", "it is important for mental and physical health", "sport is helpful to engage socially", whilst some mentioned they love the competitive aspect of sport.

The quantitative data indicates that all 50 Assistive Products were selected by the respondents as facilitating, to some extent, the participation in sports. The qualitative data shows that 45 of the $50 \mathrm{APL}$ products are named in direct relation to sports participation. 


\section{Development of a Conceptual Model of Assistive Products and Sport Participation}

Analysis of the qualitative data resulted a series of themes and subthemes. To help explain the relationship between these concepts, a model of assistive products and sport participation was developed from these concepts, a consideration of relevant literature and through research team discussion. This model, titled the Assistive Products for Participation in Sport (APPS) Model, can be seen in Figure 2, and illustrates the ways in which assistive products are used to facilitate sport participation. One way of partitioning the results is to consider them at micro, meso and macro levels; which necessary overlap but also have distinctive explanatory value (MacLachlan \& McVeigh, 2021). The model illustrates the three overarching themes: 1) sport participation (micro level); 2) support technologies (meso level); and 3) community (macro level). Sport participation is expressed as a pathway, chronologically divided onto preparation (pre-), participation (during) and post-participation (post-). Within the pathway, sport participation belongs to the micro-level, while preparation and post-participation happen within the meso-level of supporting technologies. All the three pathway components take place within the macro-level of community.

[Insert Figure 2 here]

\section{Sport Participation}

The micro-level of the APPS Model, constitutes the core of the framework and focuses on the sport participation itself. This level puts the focus on the moment of sport participation, which includes engagement in sport (i.e., watching or supporting) and sport performance (i.e., playing at a recreational or competitive level). It includes the subthemes of independence and sport-performance specific APs.

\section{Independence}

Within the context of sport participation, respondents identified the importance of using assistive products to facilitate independence. For example, one coach stated, "The lower limb prosthesis provides independence for the athlete with limb loss... And provides equal distribution of body mass which ensures balance ". This is an example of direct use of the assistive product both in the moment of sport performance, but also to facilitate independence on a day-to-day basis. Assistive products may also be used to promote moments of sport engagement. This was described by one caregiver who indicated the AP user they work with "uses items to maintain independence and dignity while out of the home" and engaging in sport as a supporter or fan. These two examples provide a sense of how assistive products are able to provide a sense of independence for the AP user across the entire spectrum of sport participation.

\section{Sport Specific AP}

In addition to those used to support independence, there are APs which are used specifically for sports performance. One participant, who used a wheelchair designed for active use, described how the wheelchair could be used to promote mobility, and allows "accessibility in sports activities like table tennis, badminton, wheelchair cricket, wheelchair basketball". The use of lower limb prostheses was described as being useful for rock climbing by another AP user, who suggested the prosthesis "makes it easier to climb a wall. Also allows me to cycle around or walk around." It was interesting to note this individual's use of their prosthesis for sport, as they also indicated it was used regularly as their every-day AP. Outside of APs for mobility, APs such as incontinence products were also described by both coaches and AP users as support for the moment of sport participation. Although these products may not always be 'seen' during sport participation, one AP-user pointed out they use incontinence products to "pursue sport with confidence". Other APs whose usage was specific to the moment of performance were alarm signallers with light/sound/vibration. These were described by one AP user as being used for "flashing lights on the court to alert the players if the referee blew the whistle as you were not allowed to wear your hearing aids." This was particularly interesting as one AP (hearing aids) was substituted for another (flashing lights) during the moment of sport participation. Those who were engaging in sport as a follower or fan also described using APs, including spectacles for "expansion of participation options".

Assistive Products are employed differently by each AP-user depending on their circumstances. Whilst a certain item might be used by one AT-user when preparing for sport performance, it may not actually be used during sport performance. For another AP user, it may be the opposite, in accordance with their needs. For instance, one AP-user pointed out they used a prosthesis to access the sports venue but indicated they "don't use it [to perform sports] in fact I take it off for both activities".

\section{Support Technologies}

The meso-level of the APPS Model, Support Technologies, includes APs used across the entire pathway of sports participation (preparation, participation, and post-participation). While these APs may not be critical to the moments of sport engagement or performance, they play a supporting role in participation. Without these support technologies, the APs surrounding sport, many would be unable to participate in sport engagement and/or performance. These technologies are used for prevention of secondary complications, ensuring safety, providing access to sporting venues and environments, and to maintain wellness.

\section{Prevention}

Multiple participants spoke about the importance of using technology to prevent conditions which impaired their sport performance. For example, a coach describing the use of therapeutic footwear suggested "this protects the foot of an athlete with diabetes from pressure sore". Similarly, a pressure relief cushion may be utilized by an AP user because it "reduces the pain in certain yoga positions". While these technologies are not critical to the performance of the sport, they provide the user with a way to prevent potential negative consequences of their participation. 
Another recurring sub-theme was Safety. Safety was important both during sport performance and engagement. For example, one coach described using" straps [in a manual wheelchair] to protect [against] falling and [promote] safety." Safety may also be considered in the larger environment of sport participation or engagement. One AP user described the use of alarm signalers with light/sound/vibration by pointing out that the spaces where they engage in sport' have flashing lights for fire alarm this would alert me to that danger".

\section{Access}

Within preparation and support technologies, many respondents also mentioned the importance of access or access to Sport. This was regularly noted for mobility technologies, which are often used to travel to and from the venue, but may not be used directly in the performance of sport. Although we often think about wheelchairs in this context, one caregiver indicated the AP user they worked with used a walking frame or walker "to get around" the sport environment, suggesting this "enhances participation." Other respondents, including one coach, suggested the use of tricycles "mobility in the community", while other coaches described the use of canes or sticks "to be independent before and after training" and to "access the venue". In this case, it is important to remember that both sport performance and sport engagement more broadly both may require independent access to a specific venue, which must often be facilitated by APs.

\section{Wellness}

The use of the AP for wellness, particularly during the post-participation period was mentioned by several participants. Wellness can be critical to both sport performance and sport engagement. As one AP-user described, their "pressure relief mattress ensures that I can sleep comfortably and get good rest prior to and during tournaments for powerchair football. Without this, I would wake many times during the night which would affect my performance when playing". When considering sport engagement, another AP-user suggested their manual wheelchair" give[s] me a chance to relax sometime while enjoying sport as observer". it was echoed by another AT user who stated: "I sit in my wheelchair anytime I am watching sport on tv or am attending a game. This is for comfort, I would not be able to sit on a standard seat in a stadium as it would be too painful and I would be unable to watch the game". The use of AP for this purpose is important to consider, as $90 \%$ of the respondents indicated they engage with sports by following sports from home.

\section{Community}

The macro-level of the APPS Model, Community, describes how AP contribute to both enabling participation in a sport community, and contributing to the meaning of sport for participants.

\section{Enabling Community}

The themes on Community encompass the other levels and the entire pathway (macro and micro levels). Enabling Community is a subtheme which suggests APs play a role in promoting engagement in a community around sport. For instance, two coaches indicated audioplayers with DAISY capability are used for "socializing independently" and "communication", each of which is critical to opportunities for sport participants to engage with other sport participants. Similarly, the Braille displays (note takers) were described by AP-users and coaches for "reading [the] newsletter" or for "reading the manual or team strategy". For AP users who become engaged in coaching, Braille writing equipment/braillers may also be used for their work sharing "rules and coaching". Each of these enables community surrounding sport which is important to the participants.

\section{Meaning}

It was clear from the responses received that sport participation was meaningful, for different reasons. This was described well by one participant who stated "I was very shy and introverted and when I started played sport it took me out of my shell and helped me [gain] confidence. I travelled a lot with sports and was proud to represent my country and also helped develop lifelong friendships with people and also gave me opportunities to work in sports for my career". Similarly, another AT-user described that sport helped them to maintain high levels of fitness to pursue active lifestyle," and further suggested this "provides confidence". The meaning of sport, facilitated by APs, was also multifaceted for many respondents. For example, one respondent shared how sport provides "mental stimulation, Fitness, and acceptance by Society as an active member of a club". Similarly, another AT-user described the benefits as including "social life, fun, friends, adventure, happiness, travel, physical/mental health, purpose". For some, engaging in sports can therefore seen as a way of "empowering me and giving me exposure to the community as it reduces isolation."

In addition to discussing the meaning of sport, respondents also reflected on the role of AT in achieving meaning through sport. Here, it is interesting to consider an unlikely technology - chairs for the shower, bath and toilet - and how it contributed to sport participation and meaning for multiple participants. One AT-user indicated "I feel peace when I get a chance to access washroom so a special chair in toilet environment attracts me to attend sport otherwise, I can fear to go". Another AT user also stated the same technology allows them to "pursue sport with confidence". Moreover, this item was mentioned many times in relation to tournaments and travelling. As ATP-user stated, "when at tournaments, I would need access to a shower chair to shower after games etc.". Without this critical, yet theoretically basic, AP, it is clear that many users may not be able to participate fully, and therefore achieve the benefits of sport participation.

\section{Discussion}


This is the first study to explore how the use of every day assistive products facilitate participation in sport. We found that every-day assistive products are highly relevant for sport's performance and engagement in sport not just at all levels of participation as shown in figure 1, but also during the moments of pre- and post- participation.

All 50 Assistive Products were selected by the respondents as facilitating, in one way or another, the participation in sports. This finding is highly relevant since it indicates that every-day Assistive Products contribute to the realization of the right to culture and sport, and to participation in community.

Moreover, out of the $50 \mathrm{APL}$ products, 45 are directly mentioned in relation to sports. This strengthens the validity of the APL list, not only as every-day products, but specifically also in facilitating participation in sports. Further research should explore these results to strengthen its validity.

The overarching themes of Sport Participation, Support Technologies and Community are all interrelated. Nonetheless, all 50 of the products enhance equitable participation in sports and thereby enable community and social inclusion.

Divergent examples within the data, challenge us to rethink many preconceptions of the types of APs relevant to sport. A wide range of AP used in a range of ways is required to support sports participation. For example, the prostheses, lower limb product, which might be one of the most obvious choices from the list when it comes to sport's performance, was selected by one respondent for accessing the venue rather than for the moment of sport performance. That this respondent indicated they did not use the prostheses for the sport (kayaking) is interesting, since it reinforces the importance of the entirety of the sports pathway of pre-, during and post-performance. However, the prostheses, lower limb product can also be a highly relevant product in sports performance itself, as another respondent states in his/her case it is very useful for a wide range of sport's participation. In either case, the prosthesis is a crucial component to the moment of performance for both AT users, since it allows access to sport as well as independence. These findings indicate that APs, such as a wheelchair, can be designed or used with a main purpose (e.g., mobility) but still be critical to sport engagement in the moment of performance.

When considering those technologies noted to be Support Technologies, we find for instance, chairs for shower/bath/toilet. Our results found these technologies may help to provide confidence to pursue sports, as well as have an encouraging effect when deciding to attend sports practice. This highlights how fundamental the pre- and post- performance aspect of sport are. Furthermore, they highlight the critical role of APs in contributing to access and the decision to engage in sports, but also safety and post-participation wellness. Similarly, incontinence products also provide security and confidence during performance. This product may have stigma surrounding its usage and might seem as a very banal product, but as our respondents have indicated, they are highly relevant to sports participation.

Another item which might not be associated directly with sports performance is the pressure relief mattresses. Once more, the pre- and post- performance aspect of participation in sport, including the importance of resting for sport performance, are highlighted as important to our respondents.

Finally, the overarching theme of Community is enabled for instance, by the alarm signallers with light / sound / vibration were helpful in prevention but also during performance since it allows a person with a hearing impairment to receive signals which he/she would otherwise miss. Other assistive products which enable community included audioplayers with DAISY capability since they are used to communicate and socialize independently. Similarly, the braille displays (note takers) are used to read newsletters and the manual or team strategy. In these cases, AP use can promote a strengthened sense of self, as well as enable community through interpersonal communication and enhanced meaning. This shows again, the inter-relatedness between not just the different levels of the model but also the pathway framework.

When exploring the literature related to disability and sport, it becomes clear that a discussion on AT is necessary for of the discussion of social inclusion in a broader sense but that there is a gap in the existing literature about social inclusion and AT. In most cases when AT is discussed in relation to disability and sport, it is depicted as very technical products aimed mostly at an elite sports level and para-athletes, but not about the vast range of ATs that are needed to engage in sports (Cooper et al., 2018; Heyward et al., 2017; Matsuwaka \& Latzka, 2019). Moreover, there is a gap in the literature when it comes to the different levels of participation with sport. In the absence of such a resource in the literature, it was necessary for our research team to define levels of participation (as seen in Figure 1). Most literature considers participation in sport merely as actively exercising/playing (Bryant \& Bryant, 2011; Evans et al., 2018) and measures participation by looking at frequency and intensity of sports performance (Department for Culture, 2010), but the inclusion of the entire spectrum, from the occasional spectator and the committed fan to the occasional participant, recreational player and competitive sportsperson seem to be missing. This study shows that people with disability engage in a great range of sport and are highly interested in following and participating in sports at all levels

Furthermore, the meaning that people with disability attribute to sport's participation is very related to independence, as well as the social aspect of it. These findings are in line with the review conducted by Bragg \& Pritchard-Wiart (2019), which reported that people who used AT to engage in sports felt a "sense of belonging", "increased physical fitness", "empowerment", as well as "enjoyment, fun and inclusion" (Bragg \& Pritchard-Wiart, 2019). According to our results, participating in sport strengthens the sense of community. To further link our findings to other literature, we find that the systematic review by Owuor et al. (2018), indicates that effective and appropriate use of AT can contribute to independence and community participation (Owuor et al., 2018). Moreover, in their article the authors discuss how "inclusion" is not about helping people "fit better" into existing parameters but how it is rather about creating opportunities. The study by Bates et al. (2019) states similarly that inclusive sport can generate context which enable community. Efforts to promote greater inclusion in sport should consider the mediating and moderating effects of assistive technology (Tebbutt et al., 2016).

Morover, the importance of AT in terms of preservation of autonomy and self-care is also reflected in the study by Maia et al. (2016) (Maia et al., 2016). Nonetheless, the traditional way of looking at social inclusion would be to look merely at the moment of performance. An assumption could be made that 
the provision of sport-specific products would enable performance, but this study shows that this is not enough. Many of the non-sport specific technologies are critical to that moment of performance in other ways. AT should not simply be an object to help people with disabilities fit into the existing society, but rather to create opportunities (Owuor et al., 2018). In order to achieve this, it is important to move further away from the medical model of disability. The medical model focuses solely on the impairment which prevents the moment of performance, and does not acknowledge the complexity of participation, and the variety of AT required to achieve that specific moment. Because, when considering the social-ecological approach (Wey, 2006) and to giving opportunities then actually, and as the results show, the entire GATE APL list, becomes relevant (Andrews; Ingram et al., 2016). Given the provisions in the UNCRPD, provision of a range of APs as suggested by the APL, are a requirement of governments to meet their commitments to a rightsbased approach to disability.

It is clear that more research is needed to understand and explore many aspects surrounding every-day assistive products in relation to disability and sport. Future research could include further exploration of the model developed in this study, as well as more in depth understanding of the role APs as a mediator or moderator of societal inclusion through sport. Other areas for further research could involve the cost-benefit of APs for sport participation, as well as the development of evidence to support funding of AT for sport participation.

In order to improve future research, it is necessary to acknowledge some of the limitations of this study. Firstly, due to the small sample size the data of this study is not representative but rather indicative. The results of this survey serve as a starting point for discussion on how to improve participation in sports for AT users around the world. Secondly, the fact that the survey was only available in English must also be recognized as a limitation in a global survey and may be reflected in the relatively high education-level of the respondents. Third, this survey did not specifically address issues surrounding access, as it focused on how APs could be relevant for Sports. Nonetheless, more research is needed on access to sports and opportunities for participation, especially on the differences between rural and urban areas.

\section{Conclusion}

The every-day assistive products from the GATE's APL are relevant in facilitating participation in sport. AP users participate in sports at all levels of participation and engage in a great variety of sports. This participation in sport through the use of AP can contribute to promoting social inclusion. Access to every-day assistive products across a range of different contexts is critical to both participation in sports and community engagement, and crucial to the realization of rights of persons with disabilities.

\section{Declarations}

Ethics: This study was reviewed and approved by the Maynooth University Social Research Ethics Committee.

\section{Funding Details}

This work was supported by Assistive Technology 2030, a consortium led by the Global Disability Innovation Hub (London) and funded by UKAID. EMS is supported by a Fellowship from the Canadian Institutes of Health Research. IDE is funding from the Irish Research Council (IRC) grant numberCOALESCE/2019/11.

\section{Disclosure Statement}

The authors report there are no competing interests to declare.

\section{Data Availability Statement}

Data from the research can be obtained by contacting the corresponding author at emma.smith@mu.ie.

\section{References}

Adams, V., \& Linke, A. (2019). Impact of exercise training on cardiovascular disease and risk. Biochimica et Biophysica Acta (BBA)-Molecular Basis of Disease, 1865(4), 728-734.

Allan, V., Smith, B., Côté, J., Ginis, K. A. M., \& Latimer-Cheung, A. E. (2018). Narratives of participation among individuals with physical disabilities: A lifecourse analysis of athletes' experiences and development in parasport. Psychology of Sport and Exercise, 37, 170-178.

Andrews, A. Supporting the elderly with declining cognitive function through digital technology.

Assembly, U. G. (2018). the UN Action Plan for Sport for Development and Peace. https://www.un.org/development/desa/dspd/wpcontent/uploads/sites/22/2018/06/14.pdf

Bailey*, R. (2005). Evaluating the relationship between physical education, sport and social inclusion. Educational review, 57(1), 71-90.

Bragaru, M., Dekker, R., Geertzen, J. H., \& Dijkstra, P. U. (2011). Amputees and sports. Sports medicine, 41(9), 721-740. 
Bragg, E., \& Pritchard-Wiart, L. (2019). Wheelchair physical activities and sports for children and adolescents: A scoping review. Physical \& occupational therapy in pediatrics, 39(6), 567-579.

Braun, V., Clarke, V., Boulton, E., Davey, L., \& McEvoy, C. (2020). The online survey as a qualitative research tool. International Journal of Social Research Methodology, 1-14.

Braun, V., Clarke, V., \& Gray, D. (2017). Innovations in qualitative methods. In The Palgrave handbook of critical social psychology (pp. 243-266). Springer.

Bryant, D. P., \& Bryant, B. R. (2011). Assistive technology for people with disabilities. Pearson Higher Ed.

Burkett, B. (2010). Technology in Paralympic sport: performance enhancement or essential for performance? British journal of sports medicine, 44(3), 215220 .

Cooper, R. A., Tuakli-Wosornu, Y. A., Henderson, G. V., Quinby, E., Dicianno, B. E., Tsang, K., Ding, D., Cooper, R., Crytzer, T. M., \& Koontz, A. M. (2018).

Engineering and technology in wheelchair sport. Physical Medicine and Rehabilitation Clinics, 29(2), 347-369.

Department for Culture, M. S., DCMS (2010). Participation, engagement and intensity of sports participants. Analysis of the Taking Part

Survey. https://assets.publishing.service.gov.uk/government/uploads/system/uploads/attachment_data/file/137993/TP_Sportparticipationreport_1_.pdf

Eigenschenk, B., Thomann, A., McClure, M., Davies, L., Gregory, M., Dettweiler, U., \& Inglés, E. (2019). Benefits of outdoor sports for society. A systematic literature review and reflections on evidence. International journal of environmental research and public health, $16(6), 937$.

England, S. (2017). Active people interactive: Analyse the date. Sport England.

Evans, M. B., Shirazipour, C. H., Allan, V., Zanhour, M., Sweet, S. N., Ginis, K. A. M., \& Latimer-Cheung, A. E. (2018). Integrating insights from the parasport community to understand optimal Experiences: The Quality Parasport Participation Framework. Psychology of Sport and Exercise, 37, 79-90.

Ginis, K. A. M., Latimer, A. E., Arbour-Nicitopoulos, K. P., Buchholz, A. C., Bray, S. R., Craven, B. C., Hayes, K. C., Hicks, A. L., McColl, M. A., \& Potter, P. J. (2010). Leisure time physical activity in a population-based sample of people with spinal cord injury part l: demographic and injury-related correlates. Archives of physical medicine and rehabilitation, 91(5), 722-728.

Heyward, O. W., Vegter, R. J., De Groot, S., \& Van Der Woude, L. H. (2017). Shoulder complaints in wheelchair athletes: A systematic review. PloS one, 12(11), e0188410.

Hill, D., Scarborough, D. M., Berkson, E., \& Herr, H. (2014). Athletic assistive technology for persons with physical conditions affecting mobility. JPO: Journal of Prosthetics and Orthotics, 26(3), 154-165.

Ingram, M., Marrone, N., Sanchez, D. T., Sander, A., Navarro, C., de Zapien, J. G., Colina, S., \& Harris, F. (2016). Addressing hearing health care disparities among older adults in a US-Mexico border community. Frontiers in Public Health, 4, 169.

MacLachlan, M., \& McVeigh, J. (2021). Macropsychology: Definition, Scope, and Conceptualization. In Macropsychology (pp. 1-27). Springer.

Magalhaes, B. L., Rosseto, L. P., Melo, T., Yasuda, E. C. R. P., Bispo, S. L., dos Santos, M. G., Oliveira, L. V. F., Oliveira-Silva, I., \& Oliveira, A. S. B.

(2019). Quality of Life among Assistive Technology Users: What is the Paralympic Sport Contribution? Journal of Exercise Physiology Online, 22(3), 57-64.

Maia, F. B., Teixeira, E. R., Silva, G. V., \& Gomes, M. K. (2016). The use of assistive technology to promote care of the self and social inclusion in patients with sequels of leprosy. PLoS neglected tropical diseases, 10(4), e0004644.

Marques, M. P., \& Alves, A. C. d. J. (2021). Investigating environmental factors and paralympic sports: an analytical study. Disability and Rehabilitation: Assistive Technology, 16(4), 414-419.

Martin Ginis, K. A., Ma, J. K., Latimer-Cheung, A. E., \& Rimmer, J. H. (2016). A systematic review of review articles addressing factors related to physical activity participation among children and adults with physical disabilities. Health psychology review, 10(4), 478-494.

Martin, J. J. (2013). Benefits and barriers to physical activity for individuals with disabilities: a social-relational model of disability perspective. Disability and rehabilitation, 35(24), 2030-2037.

Matsuwaka, S. T., \& Latzka, E. W. (2019). Summer adaptive sports technology, equipment, and injuries. Sports medicine and arthroscopy review, 27(2), 4855.

Neuert, C. E., Meitinger, K., Behr, D., \& Schonlau, M. (2021). The Use of Open-ended Questions in Surveys. Methods, data, analyses: a journal for quantitative methods and survey methodology (mda), 15(1), 3-6.

Owuor, J., Larkan, F., Kayabu, B., Fitzgerald, G., Sheaf, G., Dinsmore, J., McConkey, R., Clarke, M., \& MacLachlan, M. (2018). Does assistive technology contribute to social inclusion for people with intellectual disability? A systematic review protocol. BMJ open, 8(2), e017533. 
Saxena, S., Van Ommeren, M., Tang, K., \& Armstrong, T. (2005). Mental health benefits of physical activity. Journal of Mental Health, 14(5), 445-451.

Schalock, R. L., Verdugo, M. A., Jenaro, C., Wang, M., Wehmeyer, M., Jiancheng, X., \& Lachapelle, Y. (2005). Cross-cultural study of quality of life indicators. American Journal on Mental Retardation, 110(4), 298-311.

Simplican, S. C., Leader, G., Kosciulek, J., \& Leahy, M. (2015). Defining social inclusion of people with intellectual and developmental disabilities: An ecological model of social networks and community participation. Research in developmental disabilities, 38, 18-29.

Tebbutt, E., Brodmann, R., Borg, J., MacLachlan, M., Khasnabis, C., \& Horvath, R. (2016). Assistive products and the sustainable development goals (SDGs). Globalization and health, 12(1), 1-6.

Thomas, C. (1999). Female forms: Experiencing and understanding disability. McGraw-Hill Education (UK).

UN. (2006). Convention on the Rights of Persons with Disabilities

(CRPD). https://www.un.org/disabilities/documents/convention/convention_accessible_pdf.pdf

UN. (2015). Sustainable Development Goals. SDGs Transform Our World, 2030.

UNESCO. (2015). International Charter of Physical Education, Physical Activity and Sport. https://unesdoc.unesco.org/ark:/48223/pf0000235409

UNESCO. (2017). Kazan Action Plan. In Proceedings of the Sixth International Conference of Ministers and Senior Officials in Charge of Physical Education and Sports (MINEPS VI).

van den Berg-Emons, R. J., Bussmann, J. B., \& Stam, H. J. (2010). Accelerometry-based activity spectrum in persons with chronic physical conditions. Archives of physical medicine and rehabilitation, 91(12), 1856-1861.

Warburton, D. E., Nicol, C. W., \& Bredin, S. S. (2006). Health benefits of physical activity: the evidence. Cmaj, 174(6), 801-809.

Wasserman, D., Asch, A., Blustein, J., \& Putnam, D. (2016). Disability: Definitions, Models, Experience. U: Edward N. Zalta (ed.) The Stanford Encyclopedia of Philosophy. In: Stanford.

Wey, S. (2006). 'Working in the zone'-a social-ecological framework for dementia rehabilitation. Assistive Technology in Dementia Care. London: Hawker Publications.

WHO. (2001). International Classification of Functioning, Disability and Health. In. Geneva: World Health Organization.

WHO. (2016). USAID and International Disability Alliance. Priority assistive products list: improving access to assistive technology for everyone, everywhere. World Health Organization.[Internet].

WHO. (2018). Assitive Technology. Key facts. https://www.who.int/news-room/fact-sheets/detail/assistive-technology

WHO (2019). Global action plan on physical activity 2018-2030: more active people for a healthier world. World Health Organization.

Yelamos, G. M., Carty, C., \& MacLachlan, M. (2020). Assessing and improving the national reporting on human rights in and through Physical Education, Physical Activity and Sport (PEPAS). Revista de Psicología del Deporte, 29(2), 36-44.

\section{Figures}




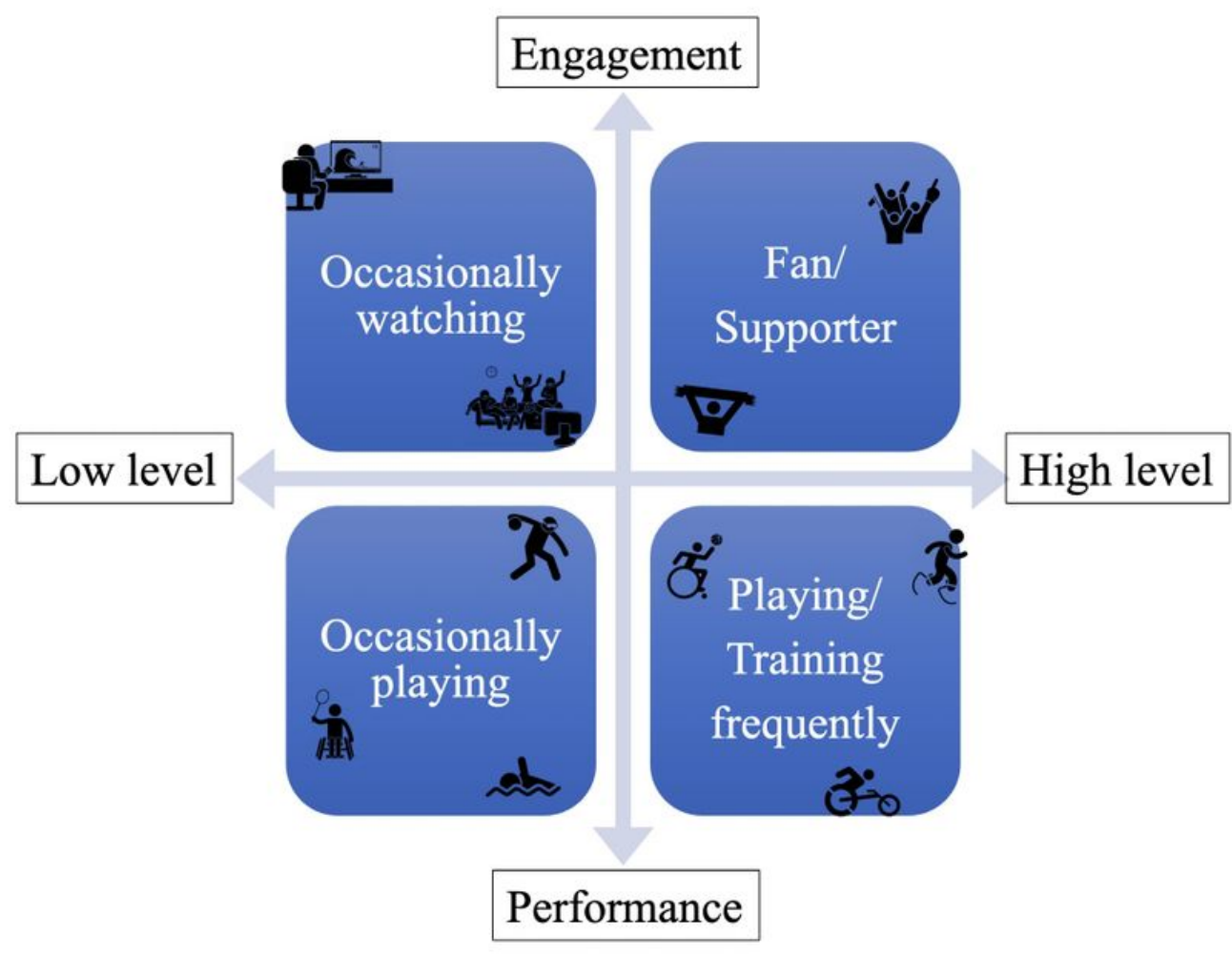

Figure 1: Types of Participation in Sport

Figure 1

Types of Participation in Sport

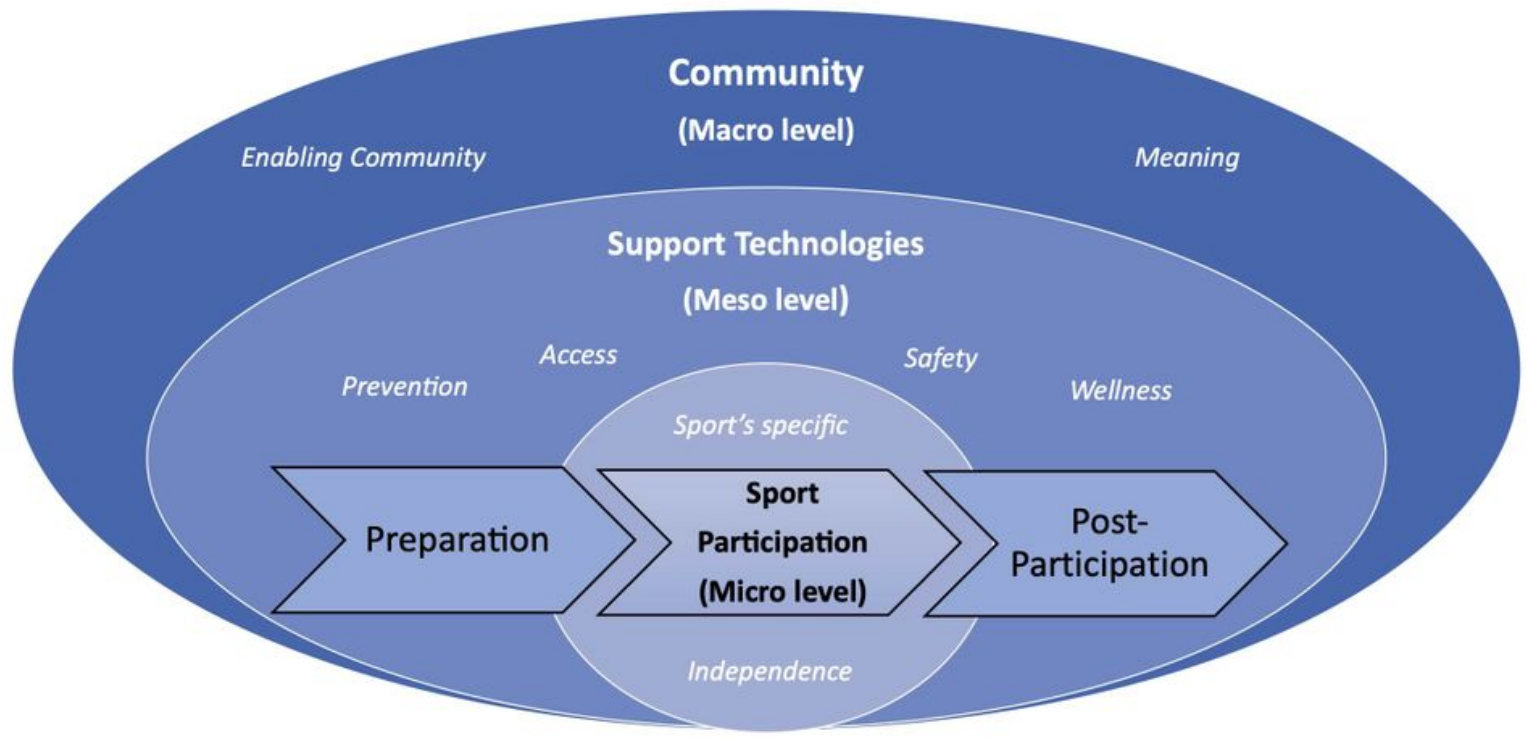

Figure 2. Assistive Products for Participation in Sport (APPS) Model

Figure 2

Assistive Products for Participation in Sport (APPS) Model 